\title{
Alexithymia in multiple sclerosis
}

\begin{abstract}
Background: An independent psychological construct like alexithymia is the least studied in multiple sclerosis (MS). The objective of this study was to determine the level of alexithymia in patients with MS and the degree of influence on it of different social and demographic characteristics of patients, including gender, age, place of residence, marital status, level of education, clinical parameters of the disease, depression and anxiety.

Materials and methods: 88 hospital patients with varying degrees of severity and type of MS were examined, according to the McDonald criteria, 2010. The following scales were used to assess the signs of depression, anxiety and alexithymia: the Beck Depression Inventory (BDI), the State-Trait Anxiety Inventory (STAI), the Toronto Alexithymia Scale (TAS-26).

Results: The prevalence of alexithymia in patients with MS was $36.36 \%$, while $34.09 \%$ represented the "marginal" group. A statistically significant positive correlation between alexithymia and depression and anxiety in patients with MS was established. High levels of alexithymia were detected with a high degree of depression on the BDI scale. None of the above socio-demographic and clinical variables influenced statistically significantly the presence of alexithymia.
\end{abstract}

Conclusion: Alexithymia can be a key psychological factor that impedes the true emotional integration of disease-related changes.

Keywords: multiple sclerosis, alexithymia, depression, anxiety
Volume II Issue 3 - 202I

\section{NG Starynets, GA Starynets}

Vinnitsa National Pirogov Memorial Medical University,

Department of Neurology and Neurosurgery of PGF,Vinnytsia, Ukraine

Correspondence: Nataliya Starynets, Docent at the Department of Neurology and neurosurgery of PGF,Vinnitsa National Pirogov Memorial Medical University, Pirogov st., 109, Vinnytsia, 21018, Ukraine, Tel +380 (93) 7509996 , Email nstarynets@ukr.net

Received: May 4, 2020 | Published: June II, 202 I

\section{Introduction}

Currently multiple sclerosis (MS) occupies a leading position among neurological diseases which are usually diagnosed in the prime of life of patients and are characterized by marked clinical polymorphism with significant behavioural and emotional disorders. ${ }^{1-4}$ MS influences all spheres of human life, including employment, relations and social life, leisure and daily activities. ${ }^{5}$ Multiple literature sources, on earlier occasions, have emphasized the importance of mood disorders and affective MS-related manifestations. ${ }^{2,6-10}$ MS is an example of an interdisciplinary problems as presence of psychiatric comorbidity in certain patients requires general assessment of a patient's status. ${ }^{11}$ More than half of patients suffering from MS feel depression. ${ }^{12-15}$ at certain stage of the disease, anxiety disorders are observed in from 36 to $57 \%$ of patients, while almost $30 \%$ of patients suffering from MS experience symptoms associated with generalized anxiety disorder. ${ }^{19,20}$ The study by Gay et al..$^{21}$ notes that anxiety is a strong predictor of depression and its influence on depression is enhanced by the presence of alexithymia as well as absence of social support.

Alexithymia is a psychological construct first described by J. Nemiah and R. Sifneos ${ }^{22}$ and based on the speech models of patients with psychosomatic disorders. Alexithymia literally means "pushing away emotions" and may be characterized by difficulties in expressing and describing feelings with an externally oriented thinking style. Alexithymia includes such peculiarities as an inability to adequately perceive and verbalize emotional states, reduced differentiation of differences between feelings and body sensations, poverty of an ability to fantasize, poverty of imagination and figurative thinking, fixation on the external events to the detriment of inner struggles. ${ }^{23} \mathrm{An}$ alexithymic individual may manifest all of the above peculiarities to an equal extent or one of them may prevail.
Diagnosis of emotive affective disorders without consideration of personality traits significantly reduces the informativeness of studies. From this point of view, such independent psychological personality trait as alexithymia is one of the least studied traits in patients with MS. There are several studies describing the level of alexithymia in patients with MS. ${ }^{24,25}$

The aim of study is to determine the level of alexithymia in patients with MS and the degree of influence on it of various social, demographic peculiarities of patients, including age, gender, place of residence, marital status, level of education, clinical parameters of the disease, depression and anxiety.

\section{Material and methods}

The study included 88 patients with a plausible diagnosis of MS under the McDonald diagnostic criteria for MS (2010) which were treated at the Neurology Department of Vinnytsia Regional Psychoneurological Hospital: 37 men and 51 woman aged from 26 to 58 years (average age was $36,2 \pm 0,65$ years). Average clinical course of the disease made $9,55 \pm 0,44$ years. Patients with absence of disorders of cognitive functions (26-30 points MMSE) fulfilled the criteria for inclusion in the study.

Clinical neurological study included determining the gravity of patients' condition based on the Kurtzke Disability Degree Status Scale. ${ }^{26}$ Psychological testing was conducted on the basis of the Minimental State Examination (MMSE), Beck's Depression Inventory (BDI), Spielberg-Hanin scale of the level of reactive (RA) and personality anxiety (PA) (STAI - State-Trait Anxiety Inventory). Level of depression and anxiety was determined as mild, moderate and marked.

Alexithymia was determined on the basis of the Toronto Alexithymia Scale (TAS-26) ${ }^{23}$ which assesses three main aspects: (1) 
difficulties of expressing feelings; (2) difficulties of describing feelings and (3) externally oriented thinking. First two factors are associated with emotional awareness and expression and, consequently, may be viewed as "affect-related", while the third factor is associated with a specific tendency to fight superficial topics and avoid affective thinking and might therefore be regarded as more cognitive. ${ }^{27}$

Patients who scored 74 or more points were considered alexithymic and patients who scored less than 62 points were considered nonalexithymic. Undetermined group consisted of patients who scored from 63 to 73 points. Marginal theoretical distribution of points was between 26 and 130. All the patients were consulted by a psychologist and a psychiatrist.

Statistical analysis was performed using the analytical system SAS 9.1 Level 1 M3 XP Home platform. Obtained data were analysed using the Pearson's chi-squared test $\left(\chi^{2}\right)$ for determining the probability of difference between relative values which are interconnected and the maximum likelihood method for discrete data ML $\chi 2$. Differences at $p<0,05$ (95\% level of significance) were considered statistically significant.

\section{Study results and their discussion}

Out of 88 examined patients with MS, the prevailing majority consisted of a group of patients with relapsing-remitting (RR) type of disease course, i.e. 69 patients $(78,4 \%)$, among them 42 patients $(60,9 \%)$ were in the exacerbation stage. 14 patients $(15,9 \%)$ had secondary progressive (SP) type of disease course and 5 patients had primary progressive (PP) type of disease course.

According to the EDSS scale, $47,7 \%$ of patients had a mild degree of disability; $37,5 \%$ of patients had a moderate degree of disability and $14,8 \%$ of patients had a severe degree of disability. Sociodemographic characteristics of patients with MS and indices under the TAS scale are given in Table 1 .

The results of testing the hypothesis regarding the connection of alexithymia with certain social and demographic peculiarities of patients with MS show that none of the described indices statistically reliably influence the alexithymic type of personality $(p>0,05)$. It was established that alexithymic type of personality was found in $32(36,36 \%)$ patients, among them $24(27,2 \%)$ of patients had a RR type of disease course, $5(5,6 \%)$ had PP type of disease course and 3 $(3,4 \%)$ had SP type of disease course. Undetermined type ("marginal" alexithymia) was observed in $23(26,1 \%)$ patients with RR and in 7 $(7,9 \%)$ with SP type of MS disease course. Non-alexithymic type of personality was observed in $22(25,0 \%)$ patients with RR and in 4 $(4,5 \%)$ with SP type of MS disease course. According to the data of statistical analysis, reverse correlation was established between the type of disease course and the presence of alexithymia $(p>0,05)$.

Connection of alexithymia with severity of patients' condition was determined on the basis of the Kurtzke Disability Status Scale and the level of depression. Indices under the TAS, EDSS and BDI scales in patients with MS are given in Table 2.

Table I Sociodemographic characteristics of patients with MS and indices under the TAS scale

\begin{tabular}{|c|c|c|c|c|c|c|}
\hline \multirow[b]{2}{*}{ Index } & \multirow{2}{*}{$\begin{array}{l}\text { with ale } \\
\text { proportion }\end{array}$} & lexithymia & \multicolumn{2}{|c|}{$\begin{array}{l}\text { Patients without alexithymia } N \\
(n=26)\end{array}$} & \multicolumn{2}{|c|}{ Marginal alexithymia $(n=30)$} \\
\hline & & $\%$ & Absolute proportion & $\%$ & $\begin{array}{l}\text { A b s o I u t e } \\
\text { proportion }\end{array}$ & $\%$ \\
\hline \multicolumn{7}{|l|}{ Gender } \\
\hline men $(n=37)$ & 12 & 37.5 & 15 & 57.7 & 10 & 33.3 \\
\hline women $(n=51)$ & 20 & 62.5 & II & 42.3 & 20 & 66.7 \\
\hline \multicolumn{7}{|l|}{ Age, years: } \\
\hline $21-30$ & 5 & 15.6 & 10 & 38.5 & 4 & 13.3 \\
\hline $31-40$ & 17 & 53.2 & 10 & 38.5 & 16 & 53.4 \\
\hline $4 I-50$ & 9 & 28.1 & 3 & 11.5 & 10 & 33.3 \\
\hline $51-60$ & I & 3.1 & 3 & 11.5 & - & - \\
\hline \multicolumn{7}{|c|}{ Place of residence: } \\
\hline city & 17 & 53.2 & 13 & 50.0 & 13 & 43.3 \\
\hline rural areas & 15 & 46.8 & 13 & 50.0 & 17 & 56.7 \\
\hline \multicolumn{7}{|l|}{ Marital status: } \\
\hline & 15 & 46.9 & 13 & & & \\
\hline \multirow{2}{*}{ single } & & & & 50.0 & 9 & 30.0 \\
\hline & 17 & 53.1 & 13 & & & \\
\hline married & & & & 50.0 & 21 & 70.0 \\
\hline
\end{tabular}




\begin{tabular}{|c|c|c|c|c|c|c|}
\hline \multirow[b]{2}{*}{ Index } & \multicolumn{2}{|c|}{ with alexithymia } & \multicolumn{2}{|c|}{$\begin{array}{l}\text { Patients without alexithymia } N \\
(n=26)\end{array}$} & \multicolumn{2}{|c|}{ Marginal alexithymia $(n=30)$} \\
\hline & Absolute proportion & $\%$ & Absolute proportion & $\%$ & $\begin{array}{l}\text { A b s o I u t e } \\
\text { proportion }\end{array}$ & $\%$ \\
\hline \multicolumn{7}{|l|}{ Level of education: } \\
\hline secondary & 5 & 15.6 & 2 & 7.7 & 4 & 13.3 \\
\hline secondary specialized & 23 & 71.9 & 17 & 65.4 & 14 & 46.7 \\
\hline higher & 4 & 12.5 & 7 & 26.9 & 12 & 40.0 \\
\hline \multicolumn{7}{|l|}{ Social status: } \\
\hline workers & 3 & 9.4 & 5 & 19.2 & 4 & 13.3 \\
\hline unemployed & 3 & 9.4 & 5 & 19.2 & 2 & 6.7 \\
\hline $\begin{array}{l}\text { Working persons with } \\
\text { disabilities }\end{array}$ & 7 & 21.8 & 5 & 19.2 & II & 36.7 \\
\hline \multicolumn{7}{|l|}{ persons with disabilities } \\
\hline financially supported by others & 19 & 59.4 & II & 42.4 & 13 & 43.3 \\
\hline
\end{tabular}

Table 2 Indices under the TAS, EDSS and BSI scales

\begin{tabular}{|c|c|c|c|c|c|c|}
\hline \multirow[b]{2}{*}{ Index of the level of severity } & \multicolumn{2}{|c|}{$\begin{array}{l}\text { Patients with alexithymia } \\
(n=32)\end{array}$} & \multicolumn{2}{|c|}{$\begin{array}{l}\text { Patients without alexithymia } \\
N(n=26)\end{array}$} & \multicolumn{2}{|c|}{ Marginal alexithymia $(n=30)$} \\
\hline & $\begin{array}{l}\text { Absolute } \\
\text { proportion }\end{array}$ & $\%$ & $\begin{array}{l}\text { Absolute } \\
\text { proportion }\end{array}$ & $\%$ & $\begin{array}{l}\text { Absolute } \\
\text { proportion }\end{array}$ & $\%$ \\
\hline \multicolumn{7}{|l|}{$\begin{array}{l}\text { Degree of disability under the } \\
\text { EDSS scale: }\end{array}$} \\
\hline mild & 13 & 40.6 & 13 & 50.0 & 17 & 56.7 \\
\hline moderate & 15 & 46.9 & 8 & 30.8 & 9 & 30.0 \\
\hline severe & 4 & 12.5 & 5 & 19.2 & 4 & 13.3 \\
\hline \multicolumn{7}{|l|}{ Depression under the BDI scale } \\
\hline \multicolumn{7}{|l|}{ without depression } \\
\hline & 5 & 15.6 & 19 & 73.1 & 18 & 60 \\
\hline mild & 5 & 15.6 & 6 & 23.1 & 6 & 20 \\
\hline moderate & 8 & 25.0 & I & 3.8 & 4 & 13.3 \\
\hline marked & 14 & 43.8 & - & - & 2 & 6.7 \\
\hline
\end{tabular}

According to the data of experimental psychological testing, nonalexithymic personality type was observed in 26 patients $(29,5 \%)$, among them $26,9 \%$ had depression of various degree of markedness, while the "marginal" group consisted of 30 patients $(34,09 \%)$ where depressive manifestations were observed in $40 \%$ of patients. 32 $(36,4 \%)$ patients were alexithymic, depression was observed in $84,37 \%$ of them.

Correlation relationship showed that alexithymia is positively related to the level of depression, while its high level was found in patients with high indices of depression under the BDI scale $(\chi 2=34,61, p<0,05)$. Results of statistical analysis have not shown a positive correlation between alexithymia and severity of patients' condition under the EDSS scale $(\chi 2=4,707, p>0,05)$, however a higher level of the degree of neurological disability was related to the presence of alexithymia.

The results of testing the patients with MS under the TAX-26 scale and STAI questionnaire are given in Table 3. 
Table 3 Indices under the Toronto alexithymic scale (TAS-26) and Spilberg-Hanin anxiety level (STAI - State-Trait Anxiety Inventory)

\begin{tabular}{|c|c|c|c|c|c|c|}
\hline \multirow{2}{*}{$\begin{array}{l}\text { Anxiety under the } \\
\text { STAI scale }\end{array}$} & \multicolumn{2}{|c|}{$\begin{array}{l}\text { Patients with alexithymia } \\
(n=32)\end{array}$} & \multicolumn{2}{|c|}{$\begin{array}{l}\text { Patients without alexithymia } \\
n(n=26)\end{array}$} & \multicolumn{2}{|c|}{ Marginal alexithymia $(n=30)$} \\
\hline & RA (\%) & PA (\%) & RA (\%) & PA (\%) & RA (\%) & PA (\%) \\
\hline mild & - & - & 7.7 & 19.2 & 10.0 & 10.0 \\
\hline moderate & 25.0 & 18.7 & 50.0 & 46.2 & 36.7 & 26.7 \\
\hline high & 75.0 & 81.3 & 42.3 & 34.6 & 53.3 & 63.3 \\
\hline
\end{tabular}

According to the results of testing under the STAI questionnaire, out of the total number of alexithymic patients, higher level of RA was found in $75,0 \%$ and PA was found in $81,3 \%$ of cases. The analysis of test results based on the STAI scale took into account the fact that moderate level of RA was regarded as an attributive norm, while its high level was assessed as a reaction to a certain situation or an emotional state characterized by feeling strain, anxiety, danger or vague threat at the present moment.

It is worth noting that positive correlation is observed in an overall sample of patients with MS between the values of TAI and STAI scores: RA $(\chi 2=9,864, p<0,05)$, PA $(\chi 2=17,165, p<0,05)$, which indicates a sufficiently high level of association of alexithymic personality type with reactive anxiety and personality anxiety.

It is worth noting that asthenic mental disorders as well as depressive manifestations, which develop with anxiety affect, start forming in patients with MS suffering from alexithymia.

\section{Conclusions}

1. Thus, the results of the above study indicate that alexithymia makes up 36,36\% of cases among patients with MS.

2. A statistically significant positive correlation relationship of alexithymia with depression and anxiety was established. High levels of alexithymia were observed in patients with high degree of depression under the BDI scale. Patients with higher level of severity under the Kurtzke disability status scale were found to be alexithymic.

3. A reverse correlation relationship between alexithymia and certain social, demographic and clinical variables in patients with MS was established.

4. Alexithymia can be a key psychological factor that impedes true emotional integration of changes associated with the disease and, therefore, requires further study.

\section{Acknowledgments}

None.

\section{Conflicts of interest}

Authors would like to state that there was no conflict of interests during the preparation of this article.

\section{References}

1. TE Shmidt, NN Yakhno. Multiple Sclerosis: Guidance for doctors. MEDpress-inform. - 2010:272 p.
2. Feinstein A. The clinical neuropsychiatry of multiple sclerosis. Cambridge University Press. 2007:265 p.

3. Arnett PA, Amanda R. Rabinowitz. Neuropsychological presentation and treatment of demyelinating disorders. In: Halligan P, Kischna U, editors. Handbook of clinical neuropsychology. Oxford: Oxford University Press. 2003:528-543.

4. SL Minden, A Feinstein, RC Kalb, et al. Evidence-based guideline: assessment and management of psychiatric disorders in individuals with multiple sclerosis. Report of the guideline development subcommittee of the american academy of neurology. Neurology. 2014;82(2):174-181.

5. Simmons RD. Life issues in multiple sclerosis. Nat Rev Neurol. 2010;6:603-610.

6. AA Asghar, KH Taber, RA Hurley, et al. Pure neuropsychiatric presentation of multiple sclerosis. Am J Psychiatry. 2004;161(2):226231.

7. OP Dahl, E Stordal, S Lydersen, et al. Anxiety and depression in multiple sclerosis. A comparative population-based study in NordTrondelag Country, Norway. Multiple Sclerosis. 2009;15(12):14951501.

8. RA Mattie, R Horwitz, G. Cutter et al. The burden of mental comorbidity in multiple sclerosis: frequent, underdiagnosed, and undertreated. Multiple Sclerosis. 2009;15:385-392.

9. S Johansson, K Gottberg, M Kierkegaard, et al. Variation in and predictors of the occurrence of depressive symptoms and mood symptoms in multiple sclerosis: a longitudinal two-year study. $B M C$ Neurol. 2016;16(32).

10. Murphy R. Neuropsychiatric syndromes of multiple sclerosis. J Neurol Neurosurg Psychiatry. 2017;88(8):697-708.

11. Osvaldo P Almeida 1, Brian Draper, Jane Pirkis, et al. Anxiety, depression, and comorbid anxiety and depression: risk factors and outcome over two years. Int Psychogeriatr. 2012;24(10):1622-1632.

12. Starynets NG. Depressive disorders in patients with multiple sclerosis]. Bulletin of morphology of Vinnytsia National Pirogov Memorial Medical University. 2010;16(3):657-661.

13. CC Beal, AK Stuifbergen, A Brown. Depression in multiple sclerosis: a longitudinal analysis. Arch Psychiatr Nurs. 2007;21(4):181-191.

14. R Viner, KM Fiest, AG Bulloch, et al. Point prevalence and correlates of depression in a national community sample with multiple sclerosis. Gen Hosp Psychiat. 2014;36(3):352-354.

15. Koch M, Patten S, Berzins S, et al. Depression in multiple sclerosis: a longitudinal study. Mult Scler. 2015;21(1):76-82.

16. Anthony Feinstein. The neuropsychiatry of multiple sclerosis. Can J Psychiatry. 2004;49(3):157-163. 
17. M Korostil, A Feistein. Anxiety disorders and their clinical corralates in multiple sclerosis patients. Multiple sclerosis. 2007;13(1):67-72.

18. Garfield AC, NB Lincoln. Factors affecting anxiety in multiple sclerosis. Disabil Rehabil. 2012;34(24):2047-2052.

19. Narineh Hartoonian, Alexandra L Terrill, Meghan L Beier. Predictors of anxiety in multiple sclerosis. Rehabil Psychol. 2015;60(1):91-98.

20. Wood B, van der Mei IA, Ponsonby AL, et al. Prevalence and concurrence of anxiety, depression and fatigue over time in multiple sclerosis. Mult Scler J. 2012;19:217-224.

21. MC Gay, P Vrignaud, C Garitte, et al. Predictors of depression in multiple sclerosis. Acta Neurol Scand. 2010;121(3):161-170.

22. Nemian JC. Psychosomatic illness and problem of communication Psychother Psychosom. 1970;18(1):154-160.
23. GJ Taylor, D Ryan, RM Bagby. Toward the development of a new selfreport alexithymia scale. Psychother Psychosom. 1985;44(4):191-199.

24. Chalah MA, Ayache SS. Alexithymia in multiple sclerosis: A systematic review of literature. Neuropsychologia. 2017;104:31-47.

25. Audred Cristina Biondo Eboni, Mariana Cardoso, Felipe Moreira Dias, et al. ACB High levels of alexithymia in patients with multiple sclerosis. Dementia neuropsychologia. 2018;12(2):212-215.

26. Kurtzke JF. Rating neurologic impairment in multiple sclerosis: an expanded disability status scale (EDSS). Neurol. 1983;33(11):1444-1452.

27. 27. D Grynberg, O Luminet, O Corneille, et al. Alexithymia in the interpersonal domain: a general deficit of empathy? Personality Individ Differ. 2010;49(8):845-850. 